\title{
Follow-up survey of general practitioners' perceptions of UK allergy services
}

\section{Michael Hazeldinea, Allison Worth ${ }^{b}$, Mark L Levyc, *Aziz Sheikh ${ }^{d}$}

${ }^{a}$ Research Student, Allergy \& Respiratory Research Group, Centre for Population Health Sciences, The University of Edinburgh, Edinburgh, Scotland, UK

b Senior Research Fellow, Allergy and Respiratory Research Group, Centre for Population Health Sciences, The University of Edinburgh, Edinburgh, Scotland, UK

' Senior Clinical Research Fellow, Allergy and Respiratory Research Group, Centre for Population Health Sciences, The University of Edinburgh, Edinburgh, Scotland, UK

${ }^{d}$ Professor of Primary Care Research \& Development, Allergy and Respiratory Research Group, Centre for Population Health Sciences, The University of Edinburgh, Edinburgh, Scotland, UK

Received 11th November 2009; revised version received 6th January 2010; accepted 8th January 2010; online 21st January 2010

\begin{abstract}
Background: A UK survey of general practitioners (GPS) in 2002 found that they perceived allergy care throughout the UK National Health Service (NHS) to be poor. We conducted a follow-up survey in 2009 to see if GPs' perceptions had changed.

Objectives: To determine GP perceptions of allergy care in the NHS in the wake of recent Government reports into allergy care, and to compare the findings of this survey to a similar survey conducted in 2002.

Methods: A cross-sectional postal survey of 500 UK GPs was conducted, using an adapted version of the 2002 questionnaire, modified to reflect recent developments in primary care.

Results: We obtained valid responses from 149 GPs, $87 \%$ of whom were based in England. 74\% were GP principals and $63 \%$ worked in training practices. Most GPs $(71 \% ; 95 \% \mathrm{Cl} 63-79)$ rated overall NHS allergy care as poor, expressing concern about both primary care and access to allergy specialists. There were no significant differences in GPs' perceptions of the quality of allergy care provided in primary $(p=0.33)$ and secondary care $(p=0.97)$ or access to specialists $(p=0.37)$, between 2002 and 2009.

Conclusion: This survey suggests that recent professional and parliamentary reviews have not led to any notable improvements in GP perceptions of UK NHS allergy services between 2002 and 2009.

(C) 2010 Primary Care Respiratory Society UK. All rights reserved.

M Hazeldine et al. Prim Care Resp J 2010; 19(1): 84-86.

doi:10.4104/pcrj.2010.00002
\end{abstract}

Keywords allergy, primary care, service provision, questionnaire survey, GPs

The full version of this paper, with online Appendix,

is available at www.thepcrj.org

\section{Introduction}

Allergic disorders are now extremely common in the UK, with recent data indicating that approximately one-third of the general population has been diagnosed with an allergic condition at some point in their lives., ${ }^{1,2}$ The proportion of children experiencing allergic problems is significantly higher than this (approximately 50\%). ${ }^{3}$

The vast majority of patients suffering from allergic disorders are treated in the community, and care for the majority of these patients will be provided almost exclusively by their general practitioner (GP) and/or practice nurse. ${ }^{4}$ However, concern has been expressed repeatedly about the lack of allergy knowledge amongst, and the training of, many primary healthcare professionals, thus resulting in poor quality of care..$^{5}$ The shortage in specialist allergy service provision has also been highlighted repeatedly as a contributory factor to the poor outcomes experienced by patients with allergic problems. ${ }^{6}$ Consequently, the majority of patients will have no local access to allergy specialists; some will be referred to organ-based specialists whilst those with multiple allergic problems may end up seeing a number of consultants.?

\footnotetext{
* Corresponding author: Professor Aziz Sheikh, Allergy \& Respiratory Research Group, Centre for Population Health Sciences, The University of Edinburgh, Doorway 3, Medical School, Teviot Place, Edinburgh EH8 9AG. Tel: +44 (0)1316648730 Fax: +44 (0)131650 9119 Email: aziz.sheikh@ed.ac.uk
} 
In 2002, the British Society of Allergy \& Clinical Immunology commissioned a UK survey of GPs which contributed to the Royal College of Physicians' (RCP) report, Allergy: the unmet need. ${ }^{8}$ A summary of the main findings from this work was reported in the peer-reviewed literature. ${ }^{9}$ The survey found that the majority of GPs perceived the provision of National Health Service (NHS) allergy care in both primary and secondary care sectors to be poor. Based on this survey (and other related work), the RCP called for an urgent review of allergy services. ${ }^{8}$ Since then, a number of UK Government reports have highlighted the need for improvements in allergy services, particularly in allergy training for primary healthcare professionals and access to specialist care. ${ }^{4,6,10}$

At the request of the House of Lords Allergy Implementation Working Party, we conducted a follow-up survey of GPs' perceptions of UK allergy care. We also compared the findings of this present survey with those from the original study conducted seven years earlier.

\section{Methods}

We conducted a cross-sectional descriptive postal survey employing similar methods to those used in our earlier survey. ${ }^{9}$ To construct our sampling frame, we obtained a database of all members of the Royal College of General Practitioners (RCGP) and from this we randomly selected 500 GPs. This was achieved by obtaining a list of RCGP members, shuffling this list to ensure that it was randomly ordered, and then selecting every 16th member. These selected GPs were sent an anonymous confidential questionnaire with an accompanying letter from the Chairman of the RCGP and a stamped addressed envelope. To optimise response rates, non-respondents were followed up with two additional mailings over a three-week period. A demographic profile of UK GPS ${ }^{11}$ indicates that $19 \%$ are members of the RCGP and that RCGP members are significantly younger and more likely to be female than the full UK GP population.

The survey did not involve any potentially invasive procedures on individuals and therefore ethical permission was not required. The GPs were fully informed and participated voluntarily with their responses kept confidential and anonymous so that they are not individually identifiable in any report or publication.

The questionnaire (see Appendix 1, available online at www.thepcrj.org) was essentially the same as that used in the
2002 survey, which had been developed in consultation with an extensive range of healthcare specialists including GPs and allergy specialists. The main modifications made were to add a question about whether GPs thought that bringing anaphylaxis within the ambit of the Quality and Outcomes Framework (QOF) would help improve anaphylaxis care, and to reduce the overall length of the questionnaire.

Descriptive statistics were used to summarise the main findings; the Chi-square test was used to compare findings with the earlier survey.

\section{Results}

Out of the 500 questionnaires distributed, 158 (32\%) were returned. Nine GPs did not complete the questionnaire due to illhealth or retirement. Therefore, from the 491 GPs who were potentially eligible, we obtained completed questionnaires from 149 (30\%). Of these, $74 \%$ were GP principals, 19\% were salaried, $5 \%$ were locums, $1 \%$ were assistants and $1 \%$ were retainees. The mean practice size was 16,654 patients. $87 \%$ of the GPs practised in England, $7 \%$ in Wales, $5 \%$ in Scotland and $1 \%$ in Northern Ireland. $63 \%$ of responding GPs worked in training practices and $5 \%$ had access to a primary care-based expert in allergy (a GP or nurse with a special interest).

There was no significant difference between responding and non-responding GPs with respect to either age $(p=0.16)$ or sex $(p=0.11)$. Respondents were also comparable to the full RCGP member population with respect to age $(p=0.06)$ and sex $(p=0.11)$.

Most GPs (71\%; 95\% CI 63-79) rated the overall provision of allergy care by the NHS as poor (Table 1); more than half of GPS rated allergy care as poor in primary care $(54 \% ; 95 \% \mathrm{Cl} 45-62)$ and in secondary care $(56 \% ; 95 \% \mathrm{Cl} 48-64)$ (see Table 1).

Only a small minority of GPs offered skin prick testing (3\%; $95 \% \mathrm{Cl} 0-6)$, whilst $64 \%(95 \% \mathrm{Cl} 56-72)$ reported availability of specific-lgE testing.

Over half $(52 \% ; 95 \% \mathrm{Cl} 44-60)$ thought that QOF incentives for anaphylaxis care would not translate into improvements in care provision.

Respondents reported that only $29 \%(95 \% \mathrm{Cl} 22-36)$ of GPs or their partners, and $9 \%(95 \% \mathrm{Cl} 4-13)$ of nurses, had received allergy training. Only $27 \%(95 \% \mathrm{Cl} 20-35)$ of GPs expressed interest in undergoing further allergy training, but almost half

Table 1. Comparison of GPs' opinions on the overall quality of NHS allergy care in 2002 and 2009, measured on a 10-point Likert scale.

\begin{tabular}{|c|c|c|c|c|c|}
\hline Care setting & $\begin{array}{c}2002 \\
\text { Mean (sd) }\end{array}$ & $\begin{array}{c}2009 \\
\text { Mean (sd) }\end{array}$ & $\begin{array}{c}2002 \\
\text { Rated Poor (scores 1-5) } \\
\text { n (\%; 95\%Cl) }\end{array}$ & $\begin{array}{c}2009 \\
\text { Rated Poor (scores 1-5) } \\
\text { n (\%; } 95 \% \mathrm{Cl})\end{array}$ & P-value \\
\hline Primary care & $5(1.8)$ & $5.2(2.0)$ & $135(59 \% ; 52-64)$ & $76(54 \% ; 45-62)$ & $p=0.33$ \\
\hline Secondary care & $5(2.1)$ & $5.0(2.1)$ & $143(62 \% ; 56-68)$ & $81(56 \% ; 48-64)$ & $p=0.93$ \\
\hline Access to specialist care & $4(2.1)$ & $3.8(2.1)$ & $186(80 \% ; 75-85)$ & 115 (79\%; 73-86) & $p=0.37$ \\
\hline Care throughout the NHS & $4(1.9)$ & $4.5(1.8)$ & $180(82 \% ; 76-86)$ & $94(71 \% ; 63-79)$ & $p=0.11$ \\
\hline
\end{tabular}


(40\%; 95\% Cl 33-48) thought they would benefit from such education.

The results showed no significant differences between the 2002 and 2009 surveys in terms of GPs' perceptions of the quality of allergy care provided in primary and secondary care, access to specialists, or overall provision of allergy care by the NHS (see Table 1).

\section{Discussion}

The results of this survey suggest that recent professional and parliamentary reviews (including the House of Lords) have not led to any notable improvements in GPs' perceptions of NHS allergy services. ${ }^{4,6,8,10}$ Concerns are still being expressed by a clear majority of GPs about the quality of primary and secondary care, access to allergists, and NHS allergy care overall.

The main strengths of this survey are the random sampling of GPs from throughout the UK, the multi-disciplinary input into the questionnaire design, and the updated information it provides on GPs' views of allergy care.

Limitations of this study include the lower response rate than in 2002. This is possibly due to a combination of recent changes in UK General Medical Services contracts for GPs, which financially rewards certain tasks (with the possible neglect of other non-incentivised tasks), and GPs' current burden of clinical and administrative work, including work relating to the recent swine flu epidemic. Nevertheless, the characteristics of responding and non-responding GPs were similar with respect to both age and sex, suggesting that the results are likely to be generalisable to the wider $8,000 \mathrm{GPs}$ who are members of the RCGP. But it is also possible that GPs who had taken the trouble to complete the questionnaire had a particular reason for doing so - either because they have a special interest in allergy care or because they look after patients who have had particularly bad experiences of NHS allergy care; in which case, generalising from these results is more difficult. However, given the very low numbers of GPs registered as having a special interest in allergy on the RCGP database $(n=5)$, the former reason seems unlikely.

Other limitations include the nature of the RCGP membership database used in this study, which comprises 19\% of the total number of UK GPs." This was different from the commercial database used in the 2002 survey (which was also not directly comparable to the UK GP population). This does therefore limit the potential to compare findings between the two time periods. However, although the results from both surveys cannot necessarily be extrapolated to the UK GP population as a whole, the remarkably similar results suggest that the nature of the databases is unlikely to have had a major impact on our findings. Finally, the questionnaire (see Appendix 1) used visual Likert scales ranging from poor at one end to excellent at the opposite end, which may in some cases have influenced the scoring of the respondents' opinions.

\section{Conclusion}

This study suggests that GPs believe that the current provision of allergy services is very similar to that in 2002 and that problems still persist throughout the NHS. The House of Lords Allergy Implementation Working Group needs to ensure that the previous recommendations - which still stand - are now implemented. However, this is likely to prove even more difficult to achieve than previously because of the economic squeeze on the NHS. Nevertheless, until these recommendations are implemented, it is likely that many patients with allergic problems will continue to receive sub-optimal care.

\section{Funding None \\ Acknowledgements}

Our thanks to the RCGP CIRC team and in particular Richard Neave who kindly supported this work. Our thanks are also due to Dr Colin Simpson, Ms X Zheng, Professor David Price and Professor Phil Hannaford who contributed to the earlier survey. Finally, we wish to express our thanks to the GPs who kindly responded to our survey.

\section{Potential conflict of interests}

AS is a member of the House of Lords Allergy Implementation Working Group and is the RCGP's Allergy Clinical Champion. MLL is the Editor-in-Chief of, and AS is an Assistant Editor of, the PCRJ; neither were involved in the editorial review of, nor the decision to publish, this article.

\section{References}

1. Gupta R, Sheikh A, Strachan DP, Anderson HR. Burden of allergic disease in the UK: secondary analyses of national databases. Clin Exp Allergy 2004;34:520-6. http://dx.doi.org/10.1111/j.1365-2222.2004.1935.x

2. Anandan C, Gupta R, Simpson CR, Fischbacher C, Sheikh A. Epidemiology and disease burden from allergic disease in Scotland: analyses of national databases. J $R$ Soc Med 2009;102:431-42. http://dx.doi.org/10.1258/ jrsm.2009.090027

3. Punekar YS, Sheikh A. Establishing the incidence and prevalence of cliniciandiagnosed allergic conditions in children and adolescents using routinely collected data from general practices. Clin Exp Allergy 2009;39:1209-16. http://dx.doi.org/10.1111/j.1365-2222.2009.03248.x

4. Department of Health. A review of services for allergy. London: Department of Health, 2006.

5. Covey D, McManus L, Mills C, Scadding G. Written evidence from Allergy UK. In: House of Lords Science and Technology Committee. Allergy Volume 2: Evidence. 6th Report of Session 2006-07. London: The Stationery Office, 2007.

6. House of Lords Science and Technology Committee. Allergy. 6th report of session 2006-2007. London: The Stationery Office, 2007.

7. Punekar YS, Sheikh A. Establishing the sequential progression of multiple allergic diagnoses in a UK birth cohort using the General Practice Research Database. Clin Exp Allergy 2009;39:1889-95. http://dx.doi.org/10.1111/ j.1365-2222.2009.03366.x

8. Royal College of Physicians. Allergy: the unmet need. A blueprint for better patient care. London: Royal College of Physicians, 2003.

9. Levy ML, Price D, Zheng X, Simpson C, Hannaford P, Sheikh A. Inadequacies in UK primary care allergy services: national survey of current provisions and perceptions of need. Clin Exp Allergy 2004;34:518-19. http://dx.doi.org/ 10.1111/j.1365-2222.2004.1945.x

10. Scottish Medical and Scientific Advisory Committee. Review of Allergy Services in Scotland. Edinburgh: Scottish Government Directorates, 2009.

11. RCGP. Key Demographic Statistics From UK General Practice. Royal College of General Practitioners. 2006. [cited 2009 August 30]. Available from: URL: http://www.rcgp.org.uk/pdf/ISS_FACT_06_KeyStats.pdf 


\section{ALLERGIC DISEASES}

\section{SURVEY QUESTIONNAIRE}

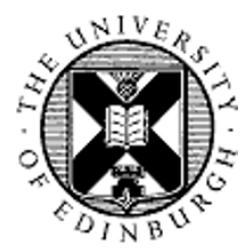

Professor Aziz Sheikh, Michael Hazeldine

Allergy \& Respiratory Research Group, Centre for Population Health Sciences: General Practice Section, University of Edinburgh

\section{CONFIDENTIAL}




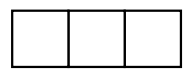

\section{SECTION A - ALLERGY CARE}

1 What do you think of the overall quality of NHS care for people with allergic disorders? $(1=$ terrible $10=$ excellent $)$

Primary Care
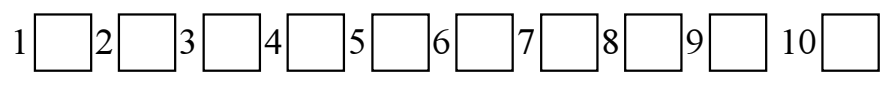

Secondary Care
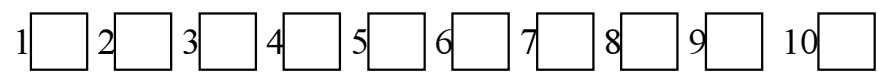

Access to Specialists
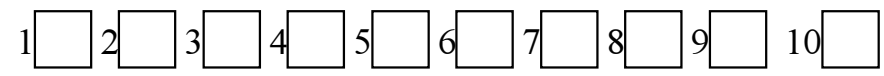

Throughout the NHS
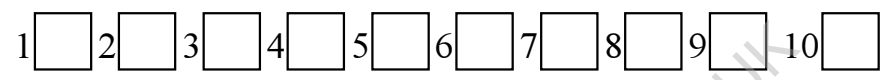

FOR ALL PARTS TO QUESTION 2 PLEASE ANSWER IN RELATION TO BOTH ADULTS AND CHILDREN

2a Does your practice have access to a local dedicated allergy clinic that provides a comprehensive service for people suffering from allergic diseases such as asthma, rhinitis, eczema, venom requiring desensitisation, food allergy or anaphylaxis?
Children: Yes
No
Don't Know
Adults:
Yes
No
Don't Know

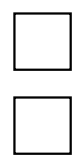

2b How far is this hospital/clinic from you? (miles)

\section{Children:}

Adults:

2c What is the current waiting time for a routine appointment?

Children:

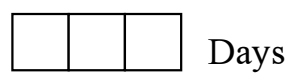

Don't Know

Adults:

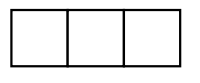

Days

Don't Know

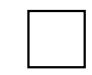

2d What is the current waiting time for an emergency appointment?

Children:

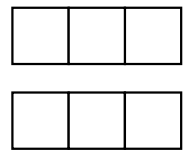

Days

Days

Adults:
Don't Know

Don't Know
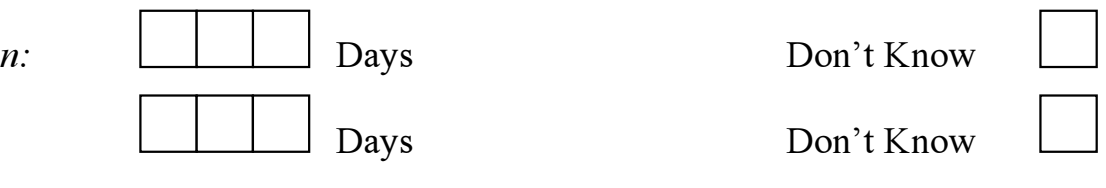
3 Does your practice offer skin prick tests for investigation of possible allergy?

Yes

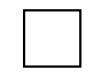

No

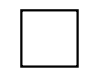

Don't Know

4 Does your practice have direct access to serum-specific IgE tests (RAST) to investigate possible allergy?

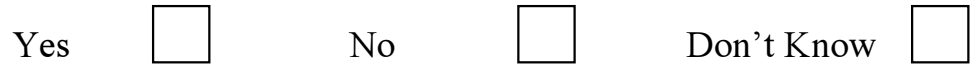

If yes, do you use these?

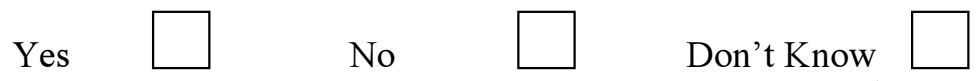

$5 \quad$ Do you have a special interest in any allergic disorder(s)?

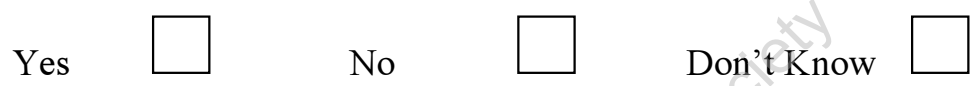

If yes, which in particular?

6 Do you have access to primary care-based expertise in allergy (e.g. GP with a special interest or an allergy nurse specialist)?

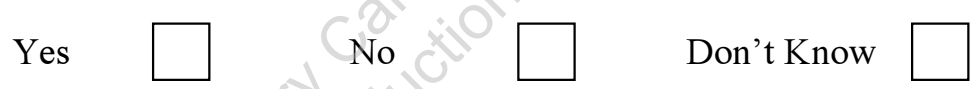

$7 \quad$ Have you or any of your partners received any training in the management of allergic disorders?

Yes

No

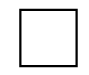

Don't Know

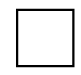

If yes, at which level

Undergraduate $\square$ Postgraduate $\square_{\text {Diploma }} \square_{\text {Degree }} \square_{\text {Short course }}$

Who provided the course and what did it entail?

8 Would you be interested in undergoing further training to take on a post as a GP with a special interest in allergy?

Yes

No

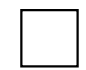

Don't Know 
9 Would you, a partner or another member of the practice team benefit from training in allergy?

You $\square$ Another Doctor $\square$ Your nurse $\square$ Another member $\square$ (please specify)

If yes, please describe the training you think is needed

How could this be delivered?

10 Have any of your practice nurses undergone any training in allergy?

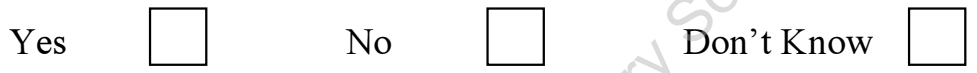

If yes, at which level

Undergraduate $\square$ Postgraduate $\square$ Short course $\square$

Who provided the training and what did it entail?

11 On a scale of 1 to 10 , how would you rate your own confidence in providing care to your patients with the following problem? $(1=$ no confidence at all 10 $=$ extremely confident)

a ASTHMA

Diagnosis

$1 \square 2 \square \square$
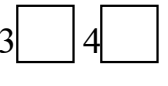

$5 \square$

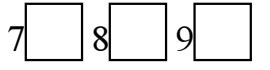

$10 \square$

Treatment
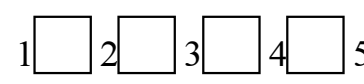

$5 \square 6$

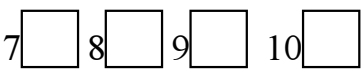

b

ALLERGIC RHINITIS

Diagnosis
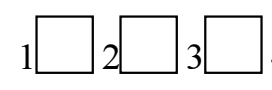

$4 \square$
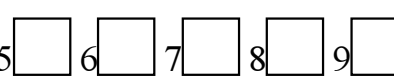

$10 \square$

Treatment
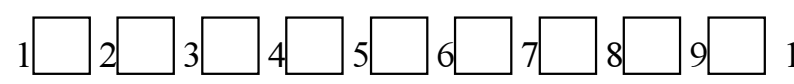

$10 \square$

c

ANAPHYLAXIS
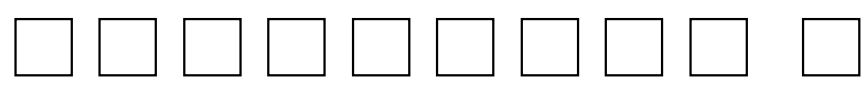
$\begin{array}{lllllllllll}\text { Diagnosis } & 1 & 2 & 3 & 4 & 5 & 6 & 7 & 8 & 9 & 10\end{array}$

Treatment

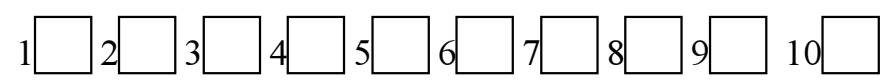

\section{d URTICARIA}

Diagnosis
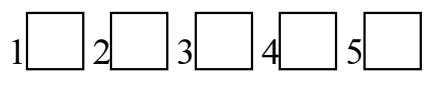

$\square 7 \square 8 \square 9 \square+10 \square$

Treatment

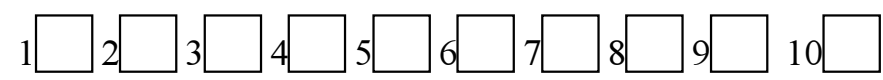

e ANGIOEDEMA

Diagnosis
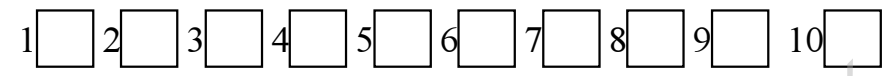

Treatment
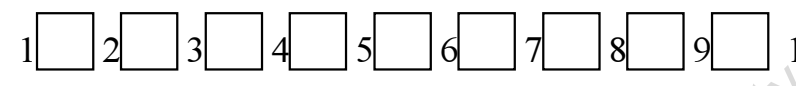

$10 \square$

f

FOOD ALLERGY

Diagnosis
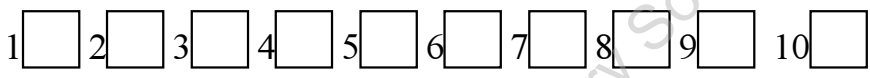

Treatment
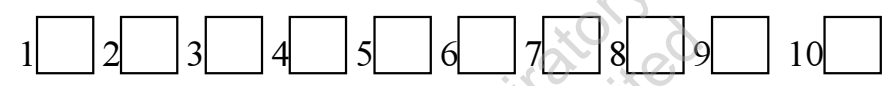

\section{g DRUG ALLERGY}

Diagnosis

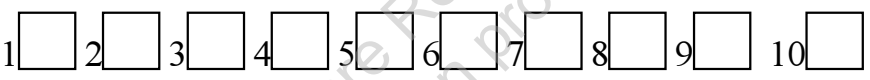

Treatment

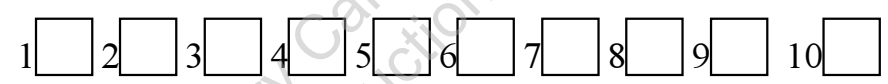

h VENOM ALLERGY

Diagnosis

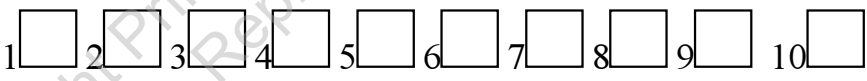

Treatment

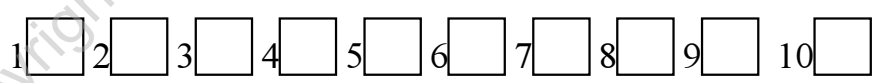

12a On a scale of 1 to 10 , how would you rate your own confidence in providing care to young children who react to foods and have special dietary requirements? $(1=$ no confidence at all $10=$ extremely confident $)$

Diagnosis

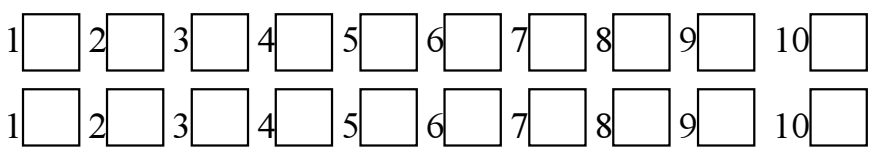

Treatment

12b Do have any children in your practice diagnosed with multiple food allergies?

Yes

No

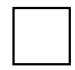

Don't Know 
If yes, approximately how many of them do you manage them yourself?

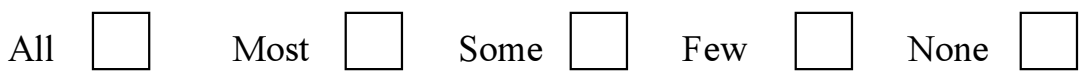

If applicable, where do you refer these children? (delete as appropriate)

Discipline/Hospital

Yes $\square$ No $\square$ Don't Know $\square$

If yes, approximately how many of them do you manage yourself?

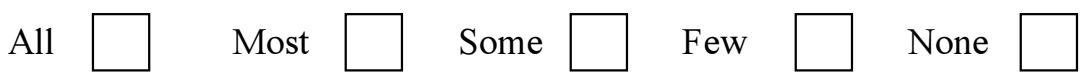

If applicable, where do you refer these children? (delete as appropriate)

Discipline/Hospital

12d Do you have any children in your practice with dietary or growth problems that you believe may be related to allergies?

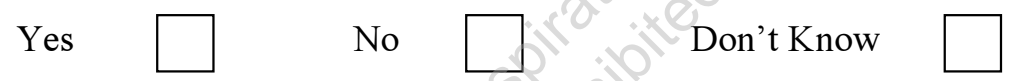

If yes, approximately how many of them do you manage yourself?

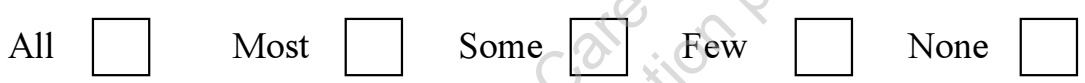

If applicable, where do you refer these children? (delete as appropriate)

Discipline/Hospital

13 Do you feel that the awarding of Quality \& Outcomes Framework (QOF) points would help to improve the care of patients with a history of anaphylaxis?

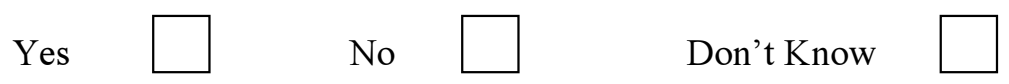

14 Do you currently prescribe adrenaline auto-injectors (e.g. Epi-pen) to patients at risk of anaphylaxis?

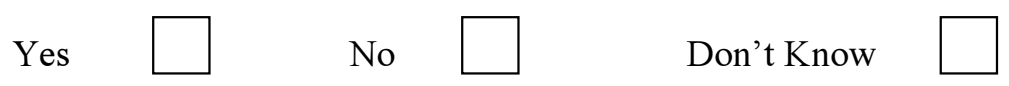

15 Are you confident in advising patients/carers how and when to use their adrenaline auto-injectors?
Yes
No

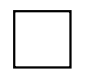
Don't Know 


\section{SECTION B - YOU AND YOUR PRACTICE}

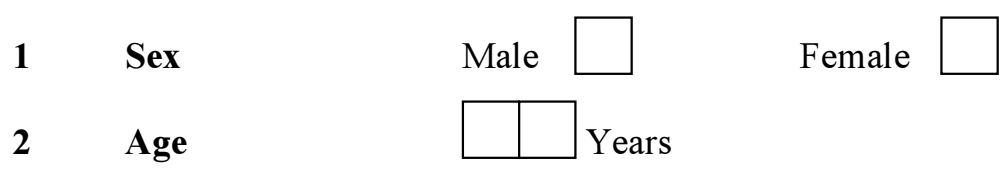

3 Do you suffer from any allergic conditions?

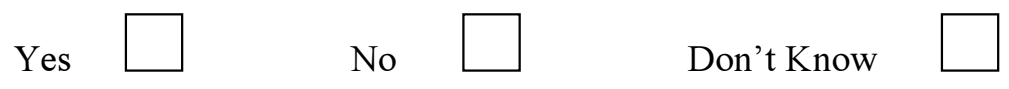

$4 \quad$ In which year did you obtain your primary medical qualification?

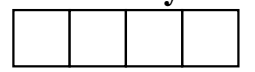

$5 \quad$ What is your ethnic origin?

White $\square$ Black Caribbean $\square$ Black African $\square$ Asian $\square$

If other please state;

$6 \quad$ Are you a member of any of the following?

The Royal College of GPs

The Royal College of Physicians
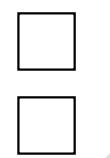

The GPIAG

The BSACI
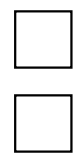

$7 \quad$ Please select from the following which best describes you

GP Principal

Assistant

Salaried GP
GP Retainer

Locum
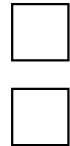

If other please state

$8 \quad$ What is the patient size of your practice?

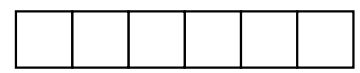

9 What is the name of your PCT?

10 How many whole time equivalent doctors work in the practice?

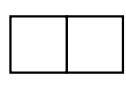

11 What is the practice post-code?

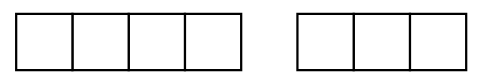

12 Do you work in 'training' practice?

Yes

No

Please feel free to make any further comments about allergy provision in the UK 